\title{
Kinetic Modeling and Optimization of a Batch Ethanol Fermentation Process
}

\section{Samuel C Oliveira ${ }^{1 *}$, Romulo C Oliveira ${ }^{2}$, Mariana V Tacin ${ }^{2}$ and Edwil AL Gattás ${ }^{2}$}

${ }^{1}$ Departamento de Bioprocessos e Biotecnologia, Faculdade de Ciências Farmacêuticas, UNESP-Univ Estadual Paulista, Rodovia Araraquara-Jaú km 1, Caixa Postal 502, CEP 14801-902, Araraquara-SP, Brazil

${ }^{2}$ Departamento de Alimentos e Nutrição, Faculdade de Ciências Farmacêuticas, UNESP-Univ Estadual Paulista, Rodovia Araraquara-Jaú km 1, Caixa Postal 502, CEP 14801-902, Araraquara-SP, Brazil

\begin{abstract}
A simple mathematical model, taking into account substrate limitation and inhibition by both the product ethanol and the substrate, was proposed and used to interpret experimental data from a batch alcohol fermentation process, conducted at two different sets of initial concentrations of sugar and cells. A detailed sequence of mathematical model derivation and parameter estimation is presented. The temporal profiles of sugar, cell and ethanol concentrations in the culture medium were modeled by a set of ordinary differential equations, which were integrated numerically by the $4^{\text {th }}$-order Runge-Kutta-Gill method. The model was validated by real laboratory fermentations and the accuracy of the model is acceptable. The agreement between the simulation and experimental results demonstrates that the model is sufficiently reliable for prediction of the dynamic behavior of the bioprocess. A study of process optimization by means of an approximate model, used to describe the dynamics of sugar consumption, revealed the need to employ a multi-objective approach, to maximize simultaneously the ethanol productivity, ethanol concentration and the conversion of sugars.
\end{abstract}

Keywords: Kinetic modeling; Ethanol fermentation; Batch reactor; Process optimization

\section{Introduction}

The rising demand for fuel ethanol calls higher production and more efficient bioprocesses. For this reason, a more complete knowledge of dynamic and static behavior is required, in order to understand, to operate, to optimize and to control ethanol fermentation processes [1]. Mathematical models have an important role to play in the optimization and control of bioethanol production processes. These process models are obtained from the mass balances and kinetic expressions that describe each operation unit (reactor). Care has to be taken with the values of the model parameters, especially the kinetic ones, so that reliable predictions can be made [2].

The simplest models formulated to describe bioprocesses are the unstructured models. In these models, it is assumed that cells are entities in solution that interact with the environment $[1,3]$. No internal cell structure is recognized, and the cell population is treated as homogeneous [1]. In structured models, the biomass structure is defined by means of more than one variable, which represent cell components, such as the RNA content, enzymes, reactants and products [3].

In comparison with unstructured models, very few structured models have been proposed to model ethanol fermentation processes. This is due to the fact that the estimation of kinetic parameters in structured models is usually complex, mainly because of nonlinearities, the large number of parameters, and interactions among them [2]. Moreover, the incorporation of more biological detail in a model makes the model more specific to a particular organism or bioprocess [4]. For these reasons, relatively simple unstructured kinetic models have frequently been used for practical applications [5]. Since these models are robust, they can be used to describe the bioprocess under various operating conditions of temperature, $\mathrm{pH}$, and other adjustable variables [5].

Batch bioprocesses, in particular, are hard to model, owing to the time-varying characteristics of biological systems, which often result in process nonlinearities. The multiplicity of reactions, adaptability and evolution of organisms over short periods of time and the continuous shift in environmental conditions are features that characterize batch processes. However, a large number of studies have been done on the modeling of batch alcoholic fermentation kinetics. Batch reactors are used firstly to identify the main phenomena (limitation, inhibition, cell death, maintenance, among others) that govern the fermentation kinetics, by performing specific experiments for this purpose. Second, the parameters in the kinetic expressions are determined; this is usually achieved by measuring the concentrations of cells, product and substrate as they vary over time and then using nonlinear regression methods to estimate the kinetic parameters. Parameter estimation is an essential step in the verification and subsequent use of a mathematical model [6].

The aim of a batch bioreactor model is to describe the variation in the environmental conditions within the bioreactor over time, and the response of the microorganism to these conditions [7]. Achieving the maximum product yield implies maintaining operating conditions within the batch fermenter close to the optimal trajectory, which is previously specified from dynamic simulations employing a mathematical model of the fermentation process. For this purpose, the model equations are solved and the values of the output variables are obtained as a function of time. Moreover, a kinetic model established

*Corresponding author: Samuel C Oliveira, Departamento de Bioprocessos e Biotecnologia, Faculdade de Ciências Farmacêuticas, UNESP-Univ Estadual Paulista, Rodovia Araraquara-Jaú km 1, Caixa Postal 502, CEP 14801-902 Araraquara-SP, Brazil, Tel: +551633014646; E-mail: samueloliveira@fcfar.unesp.br

Received January 12, 2016; Accepted January 18, 2016; Published January 22 2016

Citation: Oliveira SC, Oliveira RC, Tacin MV, Gattás EAL (2016) Kinetic Modeling and Optimization of a Batch Ethanol Fermentation Process. J Bioprocess Biotech 6 : 266. doi:10.4172/2155-9821.1000266

Copyright: () 2016 Oliveira SC, et al. This is an open-access article distributed under the terms of the Creative Commons Attribution License, which permits unrestricted use, distribution, and reproduction in any medium, provided the original author and source are credited. 
from batch experimental data is generally applied to simulate the concentration profiles of cell mass, substrate and product in fed-batch and continuous fermentation processes, in order to assess alternative operating modes [6]. Clearly, the limitation of this procedure is that the kinetic behavior of fed-batch and continuous fermentation systems is not exactly the same as that of a batch system; even so, it is possible to have a fair first approximation to the behavior of these other fermentation systems [8].

In the present study, a simple, unsegregated and unstructured mathematical model was proposed, to interpret experimental data collected from a batch alcoholic fermentation process. An important feature of the derived model is the inclusion of the ethanol produced during the fermentation (and not simply added to the system), guaranteeing the presence of intracellular ethanol, which inhibits the yeast metabolism [8]. The agreement between the simulation and independent experimental (test) results was checked in order to assess the general adequacy of the proposed mathematical model. A study on the optimization of the bioprocess was also performed.

\section{Materials and Methods}

\section{Microorganism and fermentation conditions}

Saccharomyces cerevisiae, isolated as a pure strain from commercial baker's yeast, was used to inoculate sterile medium in a fermenter, after growing under sterile conditions at $30^{\circ} \mathrm{C}$ for a period of $8 \mathrm{~h}$. Two batch fermentation experiments were carried out in a 5 L INFORS HT-Minifors bioreactor containing $2.5 \mathrm{~L}$ of medium, stirred at $120 \mathrm{rpm}$. The fermentation medium consisted of sugarcane juice (the main carbon and energy source for the yeast metabolism) supplemented with mineral nutrients and yeast extract. The fermenter and the medium were sterilized by autoclaving at $120^{\circ} \mathrm{C}$ for $30 \mathrm{~min}$. The reactor was aerated with $0.45 \mathrm{vvm}$ air, to maintain high cell viability, and the temperature was held at $30^{\circ} \mathrm{C}$ by means of a cooling block (no jacket). The initial $\mathrm{pH}$ of the medium was 4.5 and the initial sugar $\left(S_{0}\right)$ and cell $\left(X_{0}\right)$ concentrations used in the experimental runs were as follows: $S_{0}=111.5 \mathrm{~g} / \mathrm{L} ; X_{0}=25.0 \mathrm{~g} / \mathrm{L}$ for experiment $\# 1$ and $S_{0}=88.7 \mathrm{~g} / \mathrm{L}$; $X_{0}=23.9 \mathrm{~g} / \mathrm{L}$ for experiment \#2. The process was monitored by periodic samplings of the reaction mixture, to determine concentrations of residual sugars, cell mass and ethanol, as well as the cell viability. These analyses were done in triplicate. Cell concentration was determined as dry weight by spectrophotometry at $570 \mathrm{~nm}$. Sugar concentration, expressed as grams of glucose per liter, was determined by the analytical method for reducing sugars described by Miller [9], based on the use of dinitrosalicylic acid reagent. Cell viability was determined by the classical method of staining with methylene blue. Ethanol concentration was determined by the method described by Gattás et al. [10], based on the oxidation of ethanol by alcohol dehydrogenase to acetaldehyde, the coenzyme $\mathrm{NAD}^{+}$being the electron acceptor. The $\mathrm{NADH}$ formed in the reaction was measured by spectrophotometry at $340 \mathrm{~nm}$ and the determinations were calibrated with known ethanol concentrations.

\section{Mathematical modeling guidelines}

In order to effectively analyze and subsequently optimize a fermentation process, the kinetics of the process needs to be understood and then expressed in terms of equations.

The experimental data were interpreted with a mathematical model based on kinetic features commonly observed in alcohol fermentation processes, such as substrate limitation, inhibition of the metabolic activity by ethanol and substrate at high concentrations, formation of product associated with cell growth, cell death and other phenomena. Many of the kinetic models for cell growth and inhibition are based on those used in enzyme kinetics, with different meanings for the kinetic parameters. Theoretical descriptions are derived from the Monod equation $\left[\mu=\mu_{\max } S /\left(K_{S}+S\right)\right]$ with terms inserted to account for the reduction in specific growth and ethanol production rates due to inhibitory effects. Since ethanol is reported as a noncompetitive inhibitor of both yeast growth and ethanol fermentation, the saturation constants for these processes are unaffected by the alcohol concentration. All of the expressions developed for enzyme inhibition can be applied to model cell growth inhibition. Several equations describing the ethanol inhibitory effect (generically represented by the product-inhibition function $\mathrm{g}(\mathrm{P}))$ have been proposed, including linear $\left[g(P)=\left(1-P / P_{\operatorname{mox}}\right)\right]$, exponential $\left[g(P)=\exp \left(-K_{P} P\right)\right]$, hyperbolic $\left[g(P)=K_{p} /\left(K_{p}+P\right)\right]$, parabolic $\left[g(P)=\left(1-P / P_{\max }\right)^{0.5}\right]$ and other expressions, all of which are rough approximations of much more complex effects $[11,12]$. However, the ethanol-inhibition function has been more accurately represented by a power-law equation $\left[g(P)=\left(1-P / P_{\max }\right)^{n}\right]$, where $n$ is a coefficient that modulates the intensity of inhibition and so-called "toxic power".

The Monod equation predicts that the specific growth rate always continues to increase with substrate concentration, up to any value. However, in practice, the specific growth and growth-associated product formation rates usually begin to decline above some particular value of the substrate concentration, thus characterizing inhibition by substrate. Since high initial sugar concentrations are used in the production of ethanol, growth inhibition by substrate is expected to occur more in batch processes than in continuous processes, owing to the high concentrations of sugar found during the batch mode of operation, in contrast with low levels of residual sugar in continuous processes. The substrate inhibition effect is often modeled by the Andrews equation $\mu=\hat{\mu} \mathrm{S} /\left(\mathrm{K}_{\mathrm{s}}+\mathrm{S}+\mathrm{S}^{2} / \mathrm{K}_{\mathrm{i}}\right)$ which is derived from the Haldane equation for enzymatic kinetics $[4,13]$.

A simple kinetic model for specific rate of product formation $(\pi)$ was suggested by Luedeking and Piret $[\pi=\alpha \mu+\beta]$, which is based on the kinetic classification of products as associated $(\alpha>0, \beta=0)$, nonassociated $(\alpha=0, \beta>0)$ and partially-associated with cell growth $(\alpha>0$, $\beta>0)$ [12]. Specific ethanol production rate can be also described by independent equation for cell growth, with its own kinetic parameters.

Specific rate of substrate consumption $(\sigma)$ is generally given as a function of cell growth or of ethanol production specific rate, using appropriate yield coefficients and neglecting consumption of substrate for maintenance requirements.

Death cell and loss of cell viability are phenomena commonly observed in alcohol fermentation, owing to shortage of nutrients and to the deleterious effects of the ethanol. Rate of cell death or inactivation $\left(r_{d}\right)$ is generally described by first order kinetics with respect to the cell concentration itself, i.e., $r_{d}=k_{d} X$ [12].

\section{Results and Discussion}

\section{Development and validation of mathematical model}

To develop the mathematical model, the following assumptions were thus adopted: (i) perfectly mixed batch reactor;

(ii) Limitation of yeast growth by shortage of substrate;

(iii) Inhibition of yeast growth by ethanol and substrate;

(iv) No cell death or inactivation $(94 \%<$ cell viability $<97 \%)$; 
Citation: Oliveira SC, Oliveira RC, Tacin MV, Gattás EAL (2016) Kinetic Modeling and Optimization of a Batch Ethanol Fermentation Process. J Bioprocess Biotech 6: 266. doi:10.4172/2155-9821.1000266

(v) Product formation associated with cell growth (primary metabolite);

(vi) Negligible consumption of substrate for cell maintenance.

Giving the previous assumptions, the mathematical model is represented by the following equations of mass balance:

$$
\begin{aligned}
& \frac{d X}{d t}=\mu X \\
& \frac{d P}{d t}=\pi X \\
& \frac{d S}{d t}=-\sigma X \\
& \text { Where, } \mu=\left(\frac{\hat{\mu} S}{K_{S}+S+\frac{S^{2}}{K_{i}}}\right) g(P) ; \pi=\alpha \mu ; \sigma=\frac{\pi}{Y_{P / S}} ; g(P)=\left(1-\frac{P}{P_{\max }}\right)^{n}
\end{aligned}
$$

The initial conditions at the start of the batch fermentation process were as follows: $S(0)=111.5 \mathrm{~g} / \mathrm{L}, X(0)=25.0 \mathrm{~g} / \mathrm{L}$ and $P(0)=0.0 \mathrm{~g} / \mathrm{L}$.

Dividing Equation 2 by Equation 3 and inserting Equation 6 in the result of this operation is obtained an equation whose integration provides the following linear equation, since the value of $Y_{P / S}$ is constant:

$$
\Delta P=Y_{P / S}(-\Delta S) \Rightarrow Y_{P / S}=\frac{\Delta P}{(-\Delta S)}
$$

Application of Equation 8 to the experimental data resulted in an overall ethanol yield $\left(Y_{P / S}\right)$ of $0.40 \mathrm{~g} / \mathrm{g}$.

An analogous procedure can be performed involving Equations 1, 2, 5 and the following equation is obtained:

$$
\Delta P=\alpha(\Delta X)
$$

Equation 9 was used to estimate the parameter $\alpha$ by linear regression, as illustrated in the Figure 1. For this purpose, only the experimental data for the exponential phase were used, since the stationary phase does not provide relevant information about this model parameter. According to results shown in Figure 1, the estimated value of the parameter $\alpha$ is $4.87 \mathrm{~g} / \mathrm{g}$.

The estimated values of $Y_{P / S}$ and $\alpha$ are within the ranges of expected values for alcohol fermentation. In particular, the value of $Y_{P / S}$ is close to those reported by Guidini et al. [14] for five strains of flocculating yeasts identified as Saccharomyces cerevisiae. On the other hand, the value of $\alpha$ agrees well with that published by Nelson and Hamzah [15] for the parameter $Y_{X / P}(=0.235 \mathrm{~g} / \mathrm{g})$, the reciprocal of $\alpha$, i.e., $Y_{X / P}=1 / \alpha$. Lee [16], performing computer simulations for various continuous ethanol fermentation systems, without and with cell recycling, used a value for $Y_{X / P}$ of $0.16 \mathrm{~g} / \mathrm{g}$, corresponding to an $\alpha$-value of $6.25 \mathrm{~g} / \mathrm{g}$.

The remaining parameters were estimated by nonlinear regression, using Marquardt's algorithm to minimize the sum of squared residuals $(\varphi)$, defined by Equation 10:

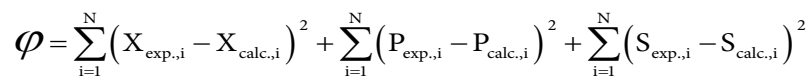

Where $N$ is the number of experimental data, subscripts exp., $i$ and calc., $i$ standing for the experimental and calculated values of the variables.

During the parameter estimation, the ordinary differential equations were integrated numerically by means of a variable-step fourth-order Runge-Kutta-Gill method in which the values of the dependent variables $(X, P, S)$ at any time $(t)$ were calculated by a

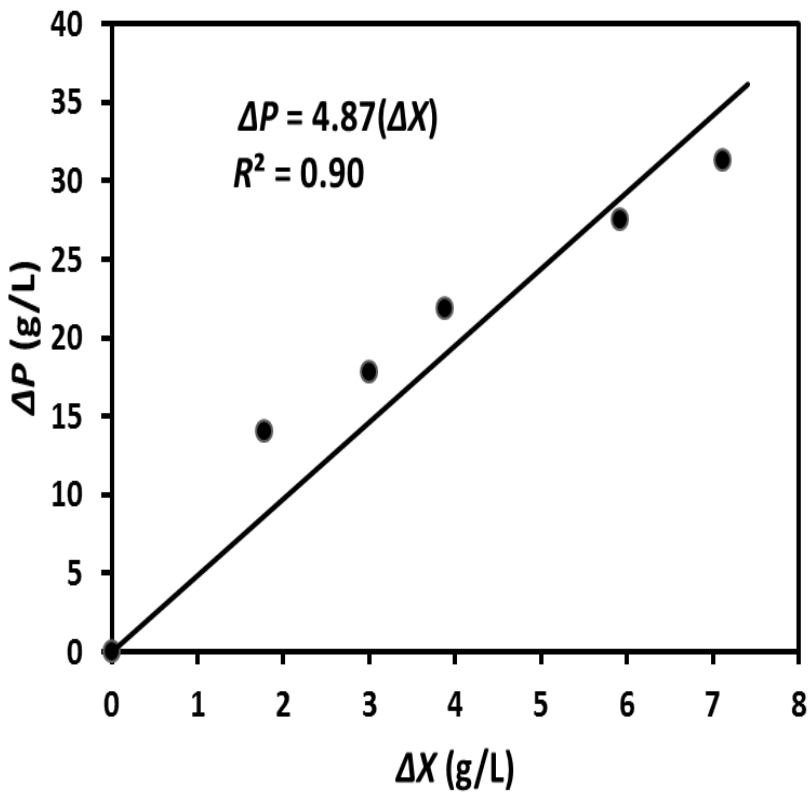

Figure 1: Estimation of parameter $\alpha$ by linear regression.
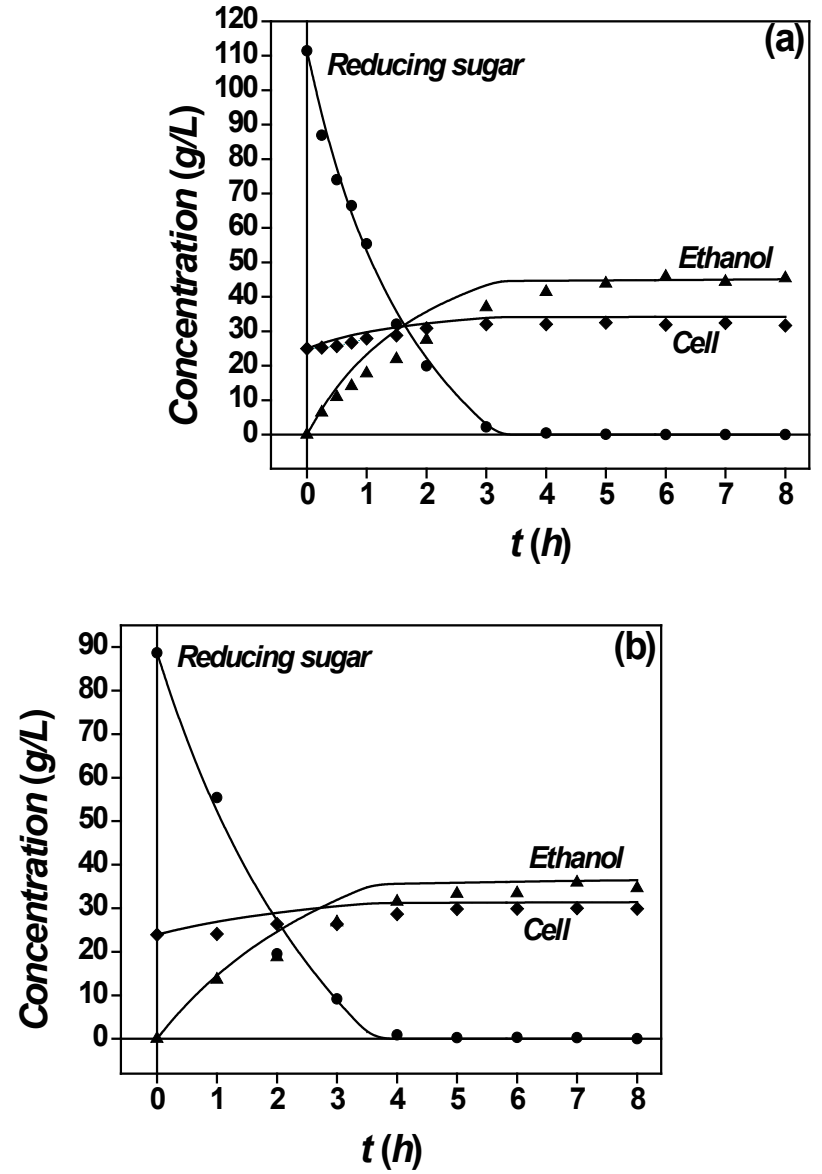

Figure 2: Experimental and predicted profiles for cell, ethanol and sugar concentrations: (a) Data for parameter estimation; (b) Data for model validation. 
series of small steps from the initial values. The step lengths in the program were chosen to satisfy the degree of accuracy required. Nonnegative constraints on the parameter values and on the calculated values of substrate concentration were introduced into the numerical subroutines.

Table 1 presents the values of the kinetic parameters estimated by nonlinear regression, with the proposed mathematical model, from the experimental data obtained in the batch process of ethanol production. The kinetic parameters are within the expected ranges, according to Oliveira et al. [11]. The very low value of $K_{S}$ indicates a high affinity of the microorganism for the substrate utilized. On the other hand, the high value of the parameter $n$ reveals strong inhibition of the yeast growth by ethanol or a very low tolerance of ethanol by the yeast strain used in the experiments.

Phenomenological consistency of the mathematical model was first assessed by inspection of Figure 2. It can be seen that typical transient concentration profiles were recorded in the fermentation medium; i.e., the substrate concentration diminished monotonically with time until its full depletion, while cell and product concentrations increased monotonically until a stationary phase was attained, in agreement with the experimental behavior of the process variables.

Figure $2 \mathrm{a}$ also shows the predictive capacity of the mathematical model developed. According to this figure, model predictions (lines) agree well with the experimental data (symbols).

In order to draw any conclusions based on the modeling work, the model itself needs to be validated, ideally, by comparison with experiments not used in the parameter estimation step [17]. A common way to assess the goodness of model fit is to use statistical indicators such as the coefficient of determination $\left(R^{2}\right)$. Although there is much discussion in the literature about the validity of using $R^{2}$ to assess the goodness of fit for a nonlinear model, this statistic can provide a fair first indication of how much of the variance in the experimental data is explained by the model. A value of $R^{2}$ closer to 1 implies that model fit is better. However, a key limitation of $R^{2}$ is that this statistic cannot determine whether the parameter estimates and predictions are biased, which is why the residual plots must be assessed. Despite this limitation, the value of $R^{2}$ has often been used to validate mathematical models of bioprocesses. Liu et al. [18] modeling an ethanol fermentation process of the second generation (SSF process), used the value of $R^{2}$ to assess the goodness of fit of the mathematical model. Table 2 presents the values of $R^{2}$ for each state variable modeled here. $Y$ stands for $X, P$ or $S$ in the formula for $R^{2}$.

In dealing with a bioprocess, the calculated values of $R^{2}$ are acceptable and favorable to validation of the proposed mathematical model. However, the validity domain of the mathematical model, a fortiori, is limited by the initial substrate concentrations employed in the batch fermentations that generated the experimental data used in the parameter estimation [19]. Figure $2 \mathrm{~b}$ shows the results of the model validation test, using an experimental data set not used in parameter estimation, with the following initial conditions: $S(0)=88.7 \mathrm{~g} / \mathrm{L}$, $X(0)=23.9 \mathrm{~g} / \mathrm{L}$ and $P(0)=0.0 \mathrm{~g} / \mathrm{L}$. It was necessary to change the value of the parameter $\hat{\mu}$ to $0.25 \mathrm{~h}^{-1}$ because fermentation process was slower in the second experiment. It can be observed that the mathematical model was able satisfactorily to reproduce the profiles of all three bioprocess variables.

The development of efficient control strategies for the main operating variables in ethanol fermentations needs accurate dynamic models. Moreover, ethanol fermentation models are useful tools to assure alcohol quality and reproducibility among batches.

The applicability of the proposed model may be extended to other process scales. Thus, the proposed model could be used on the industrial scale, with some adaptation. Indeed, other mathematical models developed from lab-scale alcoholic fermentations have been validated or tested on larger scales with good performance, highlighting their possible adaptation, by taking parameter scale-up effects into account. The metabolic patterns, as represented by Equations 4-7, are unchanged with respect to the culture procedure or fermenter scale [20]. The only changes being in the kinetic parameter values [21]. Thus, the experimental data on the industrial scale could be used to scale up parameter estimation making the proposed mathematical model more general.

In Figure 2, the experimental points represent the means of three

\begin{tabular}{|c|c|c|c|}
\hline Parameter & Notation & Unit & Estimated value \\
\hline $\begin{array}{c}\text { Maximum specific growth rate in the absence of inhibitory } \\
\text { effects }\end{array}$ & $\hat{\mu}$ & $\mathrm{h}^{-1}$ & \\
\hline Saturation constant & $K_{\mathrm{S}}$ & $\mathrm{g} / \mathrm{L}$ & \\
\hline Inhibition parameter for sugars & $K_{i}$ & $\mathrm{~g} / \mathrm{L}$ & $6.10 \times 10^{-3}$ \\
\hline Inhibition parameter for ethanol & $P_{\max }$ & $\mathrm{g} / \mathrm{L}$ & 139.7 \\
\hline Ethanol toxic power & $n$ & - & 94.2 \\
\hline
\end{tabular}

Table 1: Values of the kinetic parameters estimated by nonlinear regression.

\begin{tabular}{|c|c|}
\hline Process Variable & $R^{2}=1-\frac{S S E}{T S S}=1-\left[\frac{\sum_{\mathrm{i}=1}^{\mathrm{N}}\left(Y_{\text {exp }, \mathrm{i}}-Y_{\text {calc., }}\right)^{2}}{\sum_{\mathrm{i}=1}^{\mathrm{N}}\left(Y_{\text {exp.,i }}-\bar{Y}\right)^{2}}\right]$ \\
\hline Cell Concentration $(X)$ & 0.80 \\
\hline Ethanol Concentration $(P)$ & 0.93 \\
\hline Substrate Concentration $(S)$ & 0.99 \\
\hline
\end{tabular}

Table 2: Values of the coefficient of determination $\left(R^{2}\right)$ for each process variable. 
Citation: Oliveira SC, Oliveira RC, Tacin MV, Gattás EAL (2016) Kinetic Modeling and Optimization of a Batch Ethanol Fermentation Process. J Bioprocess Biotech 6: 266. doi:10.4172/2155-9821.1000266

Page 5 of 7

\begin{tabular}{|c|c|c|c|c|}
\hline Run & $\begin{array}{c}\boldsymbol{X}_{\mathbf{0}} \\
(\mathbf{g} / \mathbf{L})\end{array}$ & $\begin{array}{c}\mathbf{S}_{\mathbf{0}} \\
(\mathbf{g} / \mathbf{L})\end{array}$ & $\begin{array}{c}\text { Average error in } \boldsymbol{X} \\
(\mathbf{\%})\end{array}$ & $\begin{array}{c}\text { Average error in } \mathbf{S} \\
(\mathbf{\%})\end{array}$ \\
\hline$\# 1$ & 25.0 & 111.5 & 1.74 & 6.93 \\
\hline$\# 2$ & 23.9 & 88.7 & 2.86 & 4.01 \\
\hline
\end{tabular}

Table 3: Average errors in the measurements of $X, S$ and $P$ for each fermentation run.

separate determinations, whose error levels are presented in Table 3. In this table, it is observed that the average errors are within the typical maximum range in bioprocess engineering of $\pm 10 \%$ of the measured value of each variable. Error bars were omitted in Figure 2 for reasons of clarity.

\section{Optimization of the fermentation process}

The validity of the proposed model enables us to predict the optimal conditions for the fermentation process to achieve a maximum yield, and the time at which to stop it, in order to avoid excessive processing time and energy consumption during the bioprocess.

Process optimization is one the main applications of a mathematical model. The development of a bioprocess for ethanol production is generally aimed at maximizing several variables such as productivity, product concentration and substrate conversion. Although the optimization can thus have several objectives, the analysis is often restricted to one (single-objective optimization). Optimization is mathematically performed by means of an objective function, previously chosen according to the goal, which is maximized or minimized. In the present study, the ethanol productivity was chosen as the objective function to be maximized.

In order to develop the objective function it was assumed that the bioreactor is operated cyclically; that is, the process of loading fresh medium, inoculation, allowing the fermentation to precede, dumping the product and cleaning the bioreactor is repeated indefinitely. If the down time between fermentation cycles is $t$, the fermentation time $t$ required to maximize the ethanol productivity $(\operatorname{Pr})$ was determined as described in the Equations 11-17.

$$
\operatorname{Pr}=\frac{\text { ethanol concentration }}{\text { processing time }}=\frac{P}{\left(t+t_{c}\right)}
$$

Ethanol concentration is obtained from Equation 8:

$$
P=Y_{P / S}\left(S_{0}-S\right)
$$

To simplify the analytical development, the modeled profile of sugar concentration was approximated by Equation 13, which was obtained by integrating Equation 14 (generalized nonlinear decay):

$$
\begin{aligned}
& S=\left[S_{0}^{(1-\delta)}-k(1-\delta) t\right]^{1 /(1-\delta)} \\
& \frac{d S}{d t}=-k S^{\delta}
\end{aligned}
$$

Where, $k=4.37\left[(\mathrm{~g} / \mathrm{L})^{1-\delta} \mathrm{h}^{-1}\right] ; \delta=0.59$

Figure 3 shows that the behavior of the two models is very similar; so that Equation 13 can be used to illustrate the optimization procedure without loss of generality. In a more rigorous analysis, $S$ would be calculated by numerical integration of Equations 1-3, coupled with Equations 4-7.

Introducing Equation 12 in Equation 11 gives:

$$
\operatorname{Pr}=\frac{\mathrm{Y}_{\mathrm{P} / \mathrm{S}}\left(\mathrm{S}_{0}-\mathrm{S}\right)}{\left(\mathrm{t}+\mathrm{t}_{\mathrm{c}}\right)}
$$

Maximizing the ethanol productivity $(\operatorname{Pr})$, i.e., setting $d P r / d t=0$, one obtains:

$$
\frac{\mathrm{d} P r}{\mathrm{dt}}=\frac{\mathrm{Y}_{\mathrm{P} / \mathrm{S}}\left[\left(\mathrm{t}^{\mathrm{t}} \mathrm{t}_{\mathrm{c}}\right)\left(-\frac{\mathrm{dS}}{\mathrm{dt}}\right)-\left(\mathrm{S}_{0}-\mathrm{S}\right)\right]}{\left(\mathrm{t}+\mathrm{t}_{\mathrm{c}}\right)^{2}}=0
$$

From Equation 16 it can be concluded that:

$$
\left(t+t_{c}\right)\left(-\frac{d S}{d t}\right)-\left(S_{0}-S\right)=0
$$

Where $S$ and $d S / d t$ are given by Equation 13 and Equation 14, respectively

Equation 17 is implicit in $t$, but can be solved by classical methods of solution of nonlinear algebraic equations, such as the NewtonRaphson's method [22-24].

The value of $t_{c}$ depends on the scale of the bioreactor, varying from one case to another. Figure 4 shows the solution of Equation 17 and corresponding values of ethanol productivity $(\mathrm{Pr})$ and sugar conversion $\left(\xi=\left(S_{0}-S\right) / S_{0}\right)$ for different values of $t_{c}$ specified.

From Figure 4, it is clear that an increase in ethanol productivity is accompanied by a conflicting decrease in substrate conversion, which means that if it is necessary to improve the former, the latter must be allowed to get worse. Tsuji et al. [25] point out that the substrate conversion is also an important performance variable, since residual substrate in the fermenter discharge would increase the costs of raw material and of wastewater treatment. This situation calls for multiobjective optimization, in which several objectives must be optimized simultaneously in a suitable compromise. This problem is best formulated and solved by constructing a vectorial objective function, defined as:

$$
\min _{t} \boldsymbol{J}=\min _{t}\left[J_{1}, J_{2}, \ldots \ldots, J_{m}\right]^{\mathbf{T}}
$$

In the present case, the components $J_{1}, J_{2}, \ldots \ldots, J_{m}$ in Equation 18 are ethanol productivity, ethanol concentration and sugar conversion, i.e., $J_{1}=P r, J_{2}=P$ and $J_{3}=\xi$. Ethanol concentration was included because it is also an important performance variable, on account of the subsequent separation processes, which have motivated the development of many processes to increase product concentration [25].

Although multi-objective optimization is the best approach for bioprocesses, there is no unique solution. A set of optimal solutions, based on distinct criteria, can be reached and the best compromise solution should be identified and chosen.

When productivity is simulated as a function of reaction time $(t)$ for each value of $t$ specified (Figure 5), the values of the times for which productivity is maximum are the same as those shown in Figure 4, which confirms the validity of proposed optimization model. Moreover, it is noted that the larger the dead time $(t)$, the lower the productivity, which was expected since this variable contributes to decrease productivity, as may be inferred from Equation 11.

\section{Conclusions}

The experimental data from a batch bioprocess for ethanol 
Citation: Oliveira SC, Oliveira RC, Tacin MV, Gattás EAL (2016) Kinetic Modeling and Optimization of a Batch Ethanol Fermentation Process. J Bioprocess Biotech 6: 266. doi:10.4172/2155-9821.1000266

Page 6 of 7

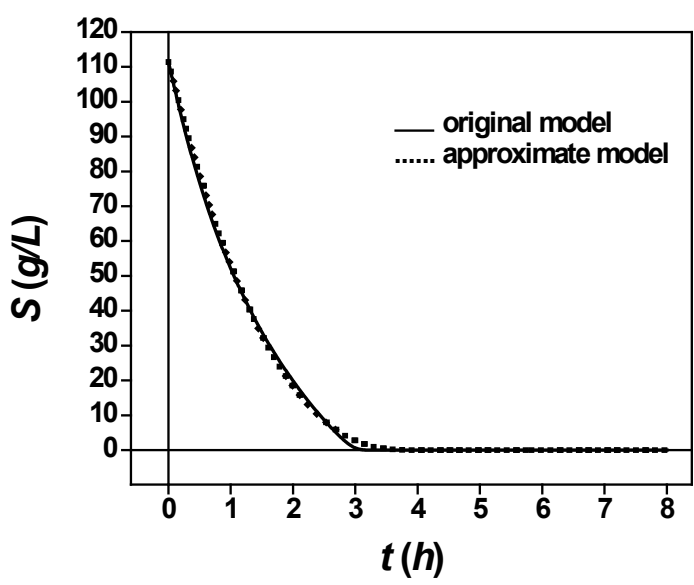

Figure 3: Comparison between the profiles of sugar concentration predicted by the original and approximate models.

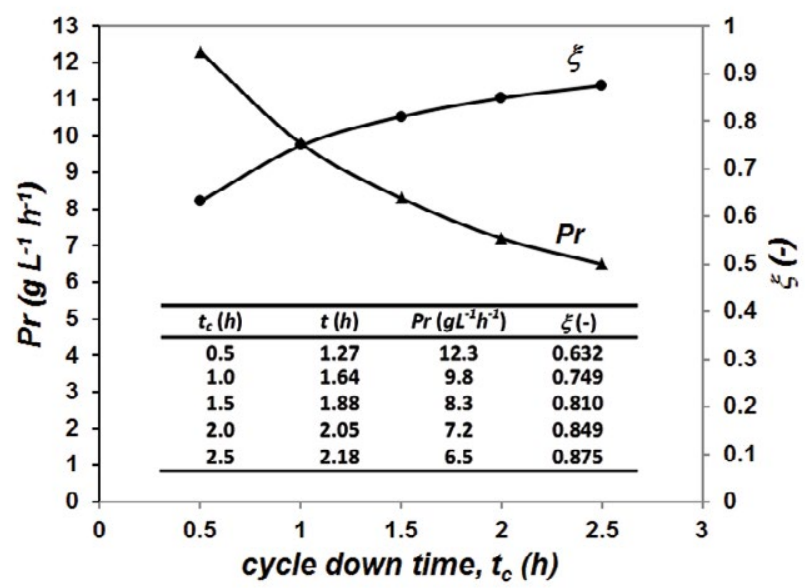

Figure 4: Single-objective optimization of batch ethanol fermentation process for optimal value of $\operatorname{Pr}$ (Pr: productivity; $\xi$ : sugar conversion).

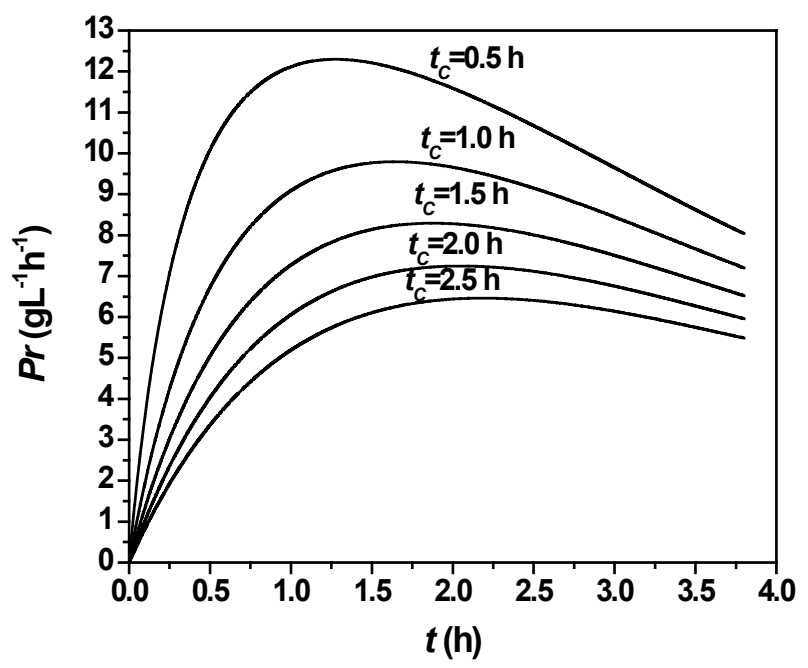

Figure 5: Productivity as a function of reaction time for different values of $t_{C}$. production were interpreted by a simple, unsegregated and unstructured mathematical model, which was used to predict the dynamic behavior and to optimize the bioprocess. The model was able to reproduce satisfactorily the behavior of the main variables of the bioprocess. It was found that it is not possible to optimize the ethanol productivity without impairing the substrate conversion, since an increase in productivity implies a reduction in conversion if a single-objective optimization strategy is employed. It is therefore most suitable in this case to employ a multi-objective optimization strategy, in which the main fermentation performance variables, such as ethanol productivity, ethanol concentration and substrate conversion, would be simultaneously optimized.

\begin{tabular}{|c|c|}
\hline$g(P)$ & Product-inhibition function (-) \\
\hline$k$ & Reaction rate constant for power-law equation $\left[(\mathrm{g} / \mathrm{L})^{1-\delta} \mathrm{h}^{-1}\right]$ \\
\hline$k_{d}$ & Specific rate of cell death or inactivation $\left(\mathrm{h}^{-1}\right)$ \\
\hline$K_{i}$ & Inhibition parameter for Andrews equation $\left(\mathrm{g} \mathrm{L}^{-1}\right)$ \\
\hline$K_{P}$ & Inhibition constant for product ( $\mathrm{g} \mathrm{L}^{-1}$ or $\mathrm{L} \mathrm{g}^{-1}$ ) \\
\hline$K_{s}$ & Saturation constant for Monod equation $\left(\mathrm{g} \mathrm{L}^{-1}\right)$ \\
\hline$n$ & Ethanol toxic power (-) \\
\hline$P$ & Ethanol concentration at time $t\left(\mathrm{~g} \mathrm{~L}^{-1}\right)$ \\
\hline$P_{\max }$ & Inhibition parameter for ethanol $\left(\mathrm{g} \mathrm{L}^{-1}\right)$ \\
\hline $\operatorname{Pr}$ & Ethanol productivity $\left(\mathrm{g} \mathrm{L}^{-1} \mathrm{~h}^{-1}\right)$ \\
\hline$r_{d}$ & Rate of cell death or inactivation $\left(\mathrm{g} \mathrm{L}^{-1} \mathrm{~h}^{-1}\right)$ \\
\hline$R^{2}$ & Determination coefficient (-) \\
\hline$S$ & Sugar concentration at time $t\left(\mathrm{~g} \mathrm{~L}^{-1}\right)$ \\
\hline$S_{0}$ & Initial sugar concentration, i.e., $S$ at $t=0\left(\mathrm{~g} \mathrm{~L}^{-1}\right)$ \\
\hline$x$ & Cell concentration at time $t\left(\mathrm{~g} \mathrm{~L}^{-1}\right)$ \\
\hline$x_{0}$ & Initial cell concentration, i.e., $X$ at $t=0\left(\mathrm{~g} \mathrm{~L}^{-1}\right)$ \\
\hline$t$ & Fermentation time $(\mathrm{h})$ \\
\hline$t_{c}$ & Down time between fermentation cycles $(\mathrm{h})$ \\
\hline$Y_{P / S}$ & $\begin{array}{l}\text { Apparent yield coefficient for substrate-to-ethanol conversion } \\
\left(\mathrm{g} \mathrm{g}^{-1}\right)\end{array}$ \\
\hline$Y_{X / P}$ & $\begin{array}{l}\text { Apparent yield coefficient based on biomass and product } \\
\text { formed }\left(\mathrm{g} \mathrm{g} \mathrm{g}^{-1}\right)\end{array}$ \\
\hline \multicolumn{2}{|c|}{ Greek letters } \\
\hline$\alpha$ & Parameter of Luedeking-Piret equation $\left(\mathrm{g} \mathrm{g}^{-1}\right)$ \\
\hline$\beta$ & Parameter of Luedeking-Piret equation $\left(\mathrm{h}^{-1}\right)$ \\
\hline$\phi$ & Sum of squared residuals $\left(\mathrm{g}^{2} \mathrm{~L}^{-2}\right)$ \\
\hline$\mu$ & Specific growth rate $\left(\mathrm{h}^{-1}\right)$ \\
\hline$\hat{\mu}$ & $\begin{array}{l}\text { Maximum specific growth rate in the absence of inhibitory } \\
\text { effects }\left(h^{-1}\right)\end{array}$ \\
\hline$\pi$ & Specific rate of ethanol production $\left(\mathrm{g} \mathrm{g}^{-1} \mathrm{~h}^{-1}\right)$ \\
\hline$\sigma$ & Specific rate of sugar (substrate) consumption $\left(\mathrm{g} \mathrm{g}^{-1} \mathrm{~h}^{-1}\right)$ \\
\hline$\xi$ & Sugar conversion (-) \\
\hline$\delta$ & Exponent for power-law equation (-) \\
\hline
\end{tabular}

\section{List of Symbols}

\section{References}

1. Paz Astudillo IC, Cardona Alzate CA (2011) Importance of stability study of continuous systems for ethanol production. J Biotechnol 151: 43-55.

2. Ccopa Rivera E, da Costa AC, Lunelli BH, Maciel MR, Maciel Filho R (2008) Kinetic modeling and parameter estimation in a tower bioreactor for bioethanol production. Appl Biochem Biotechnol 148: 163-173.

3. Charalampopoulos D, Vazquez JA, Pandiella SS (2009) Modelling and validation of Lactobacillus plantarum fermentations in cereal-based media with different sugar concentrations and buffering capacities. Biochem Eng J 44: 96 105 
Citation: Oliveira SC, Oliveira RC, Tacin MV, Gattás EAL (2016) Kinetic Modeling and Optimization of a Batch Ethanol Fermentation Process. J Bioprocess Biotech 6: 266. doi:10.4172/2155-9821.1000266

4. Bailey JE, Ollis DF (1986) Biochemical Engineering Fundamentals. 2nd edn. McGraw Hill, New York, USA.

5. Olaoye OS, Kolawole OS (2013) Modeling of the kinetic of ethanol formation from glucose biomass in batch culture with a non-structured model. Int $\mathrm{J}$ Eng Res Appl 3: 562-565

6. Wang FS, Sheu JW (2000) Multiobjective parameter estimation problems of fermentation processes using a high ethanol tolerance yeast. Chem Eng Sci 55: 3685-3695.

7. Mitchell DA, von Meien OF, Krieger N, Dalsenter FDH (2004) A review of recent developments in modeling of microbial growth kinetics and intraparticle phenomena in solid-state fermentation. Biochem Eng J 17: 15-26.

8. Bonomi A, Aboutboul H, Schmidell W (1981) Simulation of the continuous fermentation of manioc hydrolysate. Biotechnol Bioeng Symp 11: 333-357.

9. Miller GL (1959) Use of dinitrosalicylic acid reagent for determination of reducing sugar. Anal Chem 31: 426-428.

10. Gattás EAL, Ribeiro MHL, Peres MFS (2014) Improvement of the stability of the alcohol dehydrogenase from baker's yeast using polymers and salts for alcohol determination in beverages. J Food Agric Environ 12: 80-83.

11. Oliveira SC, Paiva TC, Visconti AE, Giudici R (1998) Discrimination between ethanol inhibition models in a continuous alcoholic fermentation process using flocculating yeast. Appl Biochem Biotechnol 74: 161-172.

12. Sinclair GG, Kristiansen B (1987) Fermentation kinetics and modeling. Taylor \& Francis, New York, USA.

13. Burhan N, Sapundzhiev TS, Beschkov V (2005) Mathematical modelling of cyclodextrin-glucanotransferase production by batch cultivation. Biochem Eng J 24: 73-77.

14. Guidini CZ, Marquez LD, de Almeida Silva H, de Resende MM, Cardoso VL, et al. (2014) Alcoholic fermentation with flocculant Saccharomyces cerevisiae in fed-batch process. Appl Biochem Biotechnol 172: 1623-1638.
15. Nelson MI, Hamzah N (2013) Performance evaluation of bioethanol production trough continuous fermentation with a settling unit. J Energ Power Eng 7: 20832088.

16. Lee JM (1985) Computer simulation in ethanol fermentation. In: Biotechnology applications and research. Cheremisinoff PN, Ouellette RP (Eds). Technomic Publishing Company Inc. pp: 78-87.

17. de Oliveira SC, de Castro HF Visconti AE, Giudici R (2015) Mathematical modeling of a continuous alcoholic fermentation process in a two-stage tower reactor cascade with flocculating yeast recycle. Bioprocess Biosyst Eng 38 469-479.

18. Liu D, Xu L, Xiong W, Zhang HT, Lin CC, et al. (2014) Fermentation process modeling with Levenberg-Marquardt algorithm and Runge-Kutta method on ethanol production by Saccharomyces cerevisiae. Math Probl Eng 2014: 1-10.

19. Letisse F, Lindley ND, Roux G (2003) Development of a phenomenological modeling approach for prediction of growth and xanthan gum production using Xanthomonas campestris. Biotechnol Prog 19: 822-827.

20. Aiba S, Humphrey A, Millis N (1973) Biochemical Engineering. 2nd edn Academic Press, New York, USA

21. Oliveira SC, de Castro HF, Visconti AES, Giudici R (1999) Continuous ethano fermentation in a tower reactor with flocculating yeast recycle: scale-up effects on process performance, kinetic parameters and model predictions. Bioprocess Eng 20: 525-530.

22. Bequette BW (1998) Process Dynamics: Modeling, Analysis and Simulation Prentice Hall PTR, Upper Saddle River, USA.

23. Constantinides A, Mostoufi N (1999) Numerical methods for chemical engineers with MATLAB applications. Prentice Hall PT, Upper Saddle River, USA.

24. Ramirez WF (1989) Computational methods for process simulation, Butterworth Publishers, Stoneham.

25. Tsuji S, Shimizu K, Matsubara M (1987) Performance evaluation of ethanol fermentor systems using a vector-valued objective function. Biotechnol Bioeng 30: $420-426$. 